\title{
Use of GGBS as Partial Replacement of Cement in Concrete While using Master REHO Build 823PQ
}

\author{
Praveen Kumar Gahlot, Suresh singh Sankhla, Krishan Kumar Saini
}

\begin{abstract}
Currently cement is the most important material in the construction sector. Ordinary Portland cement is one of the main ingredients used for the production of concrete. Unfortunately, production of cement involves emission of large amounts of carbon-dioxide gas into the atmosphere, a major contributor of greenhouse effect and consequent global warming. While, cement typically comprises only $12 \%$ of the concrete mass, it accounts for approximately 93\% of the total embodied energy of concrete and $6 \%$ to $7 \%$ of the world wide Carbon dioxide $\left(\mathrm{CO}_{2}\right)$ emissions. Hence, it is of utmost importance to either search for another cementitious material or partially replace it by some other material. Currently there is a trend of usage of waste products such as fly ash from coal industries, GGBS from iron smelting process, paper ash from paper industry etc as supplementary cementitious materials to enhance the properties of concrete while also effectively reducing the carbon foot print. Ground Granulated Blast Furnace Slag (GGBS) is a by-product from iron smelting process using the blast-furnace. The present paper is prepared to study the effect on compressive strength of concrete due to partial replacement of cement with GGBS as supplementary cementitious material while using master REHO build 823PQ.
\end{abstract}

Keywords: Concrete, Strength, Ground Granulated Blast Furnace Slag, greenhouse effect, Cement.

\section{INTRODUCTION}

The most widely used construction material in today's world is concrete. It is primarily composed of Portland cement, aggregates and water. Although Portland cement typically comprises only $12 \%$ of the concrete mass, it accounts for approximately $93 \%$ of the total embodied energy of concrete and accounts for $6 \%$ to $7 \%$ of the world wide Carbon dioxide $\left(\mathrm{CO}_{2}\right)$ emissions. If this embodied energy of

Revised Manuscript Received on February 05, 2020

* Correspondence Author

Praveen Kumar Gahlot*, structural department, MBM Engineering College or Jai Narain Vyas University, jodhpur, India. Email: praveenkrgahlot07@gmail.com

Dr Suresh Singh Sankhla, department, structural department, MBM Engineering College or Jai Narain Vyas University, jodhpur, India. Email: er.suresh.sankhla@gmail.com.

Krishan kumar saini, structural department, MBM Engineering College or Jai Narain Vyas University, jodhpur, India. Email: krishnacivilengineer@gmail.com.

(c) The Authors. Published by Blue Eyes Intelligence Engineering and Sciences Publication (BEIESP). This is an open access article under the CC BY-NC-ND license (http://creativecommons.org/licenses/by-nc-nd/4.0/) concrete can be lowered without deteriorating the performance and/or increasing the cost, significant environmental and economic benefits may be reaped. Immense benefits have been reaped due to utilization of Pozzolanic materials in concrete as a partial replacement of cement, mainly on account of the improvements in the long-term durability of concrete. With the aim of conserving energy by way of promoting the use of industrial wastes or by-products, which contain amorphous silica in its chemical composition, as mineral admixture for use as partial replacement of cement, many efforts are being made throughout the world

During hydration of cement, Tricalcium silicates $\left(\mathrm{C}_{3} \mathrm{~S}\right)$ and Dicalcium silicates $\left(\mathrm{C}_{2} \mathrm{~S}\right)$ react with water and produces calcium silicate hydrates (CSH gel as it is popularly known) and calcium hydroxide. This calcium hydroxide $\left(\mathrm{Ca}(\mathrm{OH})_{2}\right)$ is not a desirable product in the concrete mass and it constitutes 20 to $25 \%$ of the volume of solids in the hydrated phase which is soluble in water. Due to its soluble nature calcium hydroxide may get leached out and thus it makes the concrete porous, weak and non-durable. $\mathrm{Ca}(\mathrm{OH})_{2}$ also reacts with sulphates present in water or soil to form calcium sulphates which further react with Tricalcium Aluminates $\left(\mathrm{C}_{3} \mathrm{~A}\right)$ and cause deterioration of concrete. This deteriorating effect of calcium hydroxide can be reduced by inclusion of pozzolanic materials. The mineral admixtures such as fly ash, GGBS and silica fumes are mainly used to overcome these adverse effects of calcium hydroxide produced during the hydration of cement in concrete. These mineral admixtures react with calcium hydroxide to produce more calcium silicate hydrate thus enhancing micro structure and overall performance. The pozzolanic reaction of these mineral admixtures improves the durability of cement paste by making the paste denser and impervious. Hence, mineral admixtures which when used in optimum proportions improve the quality of concrete by:

Lowering the heat of hydration and thermal shrinkage.

Increasing the water tightness.

Reducing the scope for alkali - aggregate reaction.

Improving the chemical resistance.

Improving the corrosion resistance.

Improving the early strength, workability and extensibility. Improving the rate of strength development

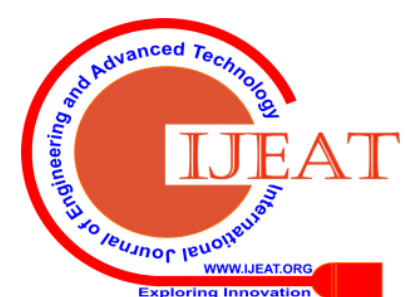




\section{Use of GGBS as Partial Replacement of Cement in Concrete While using Master REHO Build 823PQ}

\section{REACTION MECHANISM OF GROUND GRANULATED BLAST FURNACE SLAG}

Ground Granulated Blast Furnace Slag is a by-product of iron manufacturing industry.

Iron ore, coke and limestone are fed into the furnace, and the resulting molten slag floats over the molten iron at a temperature of about $1500^{\circ} \mathrm{C}$ to $1600^{\circ} \mathrm{C}$. The molten slag has a composition of $30 \%$ to $40 \%$ Silicon Dioxide $\left(\mathrm{SiO}_{2}\right)$ and approximately $40 \%$ Calcium Oxide $(\mathrm{CaO})$, which is close to the chemical composition of Portland cement. In India, we produce about 7.8 million tons of GGBS. The disposal of such huge quantities of slag even as a waste fill is big problem and may cause serious environmental hazards with the projected economic growth and development in the steel industry. When used in concrete, GGBS being a cementations material can act as a partial substitution for Portland cement without significantly compromising on compressive strength. This replacement of Portland cement with GGBS will lead to a significant reduction of carbon dioxide gas emission which would also provide environmental and economic benefits with required workability, durability and strength necessary for the design of the structures.

GGBS is a hydraulically latent material, in the presence of lime contributed from cement, a secondary reaction involving glass (Calcium Alumina Silicates) components sets in. As a consequence of this, cementitious compounds are formed. They are categorized as secondary C-S-H gel. The interaction of GGBS and Cement in presence of water is described below:

OPC (C3S/C2S) + H2O-------------C-S-H + Ca (OH)2
GGBS (C2AS/C2MS) + H2O ----------C-S-H + SiO2
$\mathrm{SiO} 2+\mathrm{Ca}(\mathrm{OH}) 2+\mathrm{H} 2 \mathrm{O}-\mathrm{C}-\mathrm{S}-\mathrm{H}$

The generation of secondary gel results in supply of additional C-S-H, a principal binding material. This is the main attribute of GGBS, which contributes to the strength and durability of the structure.

\section{AIM OF THE STUDY}

The main purpose of the study is to provide practical guidance about the effects on compressive strength of two concrete mixes (M-30 and M-35) with varying percentage of supplementary cementations material of Ground-granulated blast-furnace slag (GGBS) and water reducing admixture called as plasticizer used for improving the workability at lower water-cement ratios without affecting the compressive strength.

\section{EXPERIMENTAL PROGRAMME}

\section{A. Cement}

Shree Cement OPC of Grade 53 was used in the work. The various physical \& mechanical properties of cement were tested in accordance with test procedures prescribed in IS 4031:1968 and results so obtained are tabulated in Table I below.

Table I: Properties of Cement

\begin{tabular}{lll}
$\begin{array}{l}\text { S. } \\
\text { No. }\end{array}$ & PROPERTY & VALUES \\
\hline 1 & Specific Gravity & 3.15 \\
2 & Standard Consistency & $30 \%$ \\
3 & Initial Setting Time & 88 minutes \\
4 & Final Setting Time & 210 minutes \\
5 & Compressive Strength & $57.06 \mathrm{~N} / \mathrm{mm}^{2}$ \\
\hline
\end{tabular}

\section{B. Granulated Blast Furnace Slag (GGBS)}

Ground Granulated blast furnace slag is obtained during the manufacturing process of iron in blast furnace. The slag is a mixture of lime, silica, and alumina, the same oxides that make up Portland cement, but not in the same proportion.

TABLE II: Properties of GGBS (JSW Cemented ltd. Maharashtra)

\begin{tabular}{lll}
\hline S. & PROPERTY & VALUES \\
No. & & \\
\hline 1 & Colour & Off white \\
2 & Specific Gravity & 2.89 \\
3 & Bulk Weight (ton per $\mathrm{m}^{3}$ ) & $1.0-1.3$ \\
\hline
\end{tabular}

\section{Plasticizer}

Water reducing admixture called as plasticizer are used for improving the workability at lower water-cement ratios without affecting the compressive strength. Plasticizers are essential components to provide necessary workability. The plasticizers used here is BASF MASTER REHO BUILD 823PQ based on second generation. Its properties are given in table below.

Table III: Property of Plasticizer

\begin{tabular}{lll}
\hline S. No. & PROPERTY & VALUES \\
\hline 1 & Aspect & $\begin{array}{l}\text { Dark brown free } \\
\text { flowing liquid }\end{array}$ \\
& & $1.21 \pm 0.02$ at $25^{0}$ \\
3 & Relative density & $7 \pm 1$ \\
4 & pH & $<0.2 \%$ \\
\hline
\end{tabular}

\section{Fine Aggregate}

River sand was used as fine aggregate. IS 383:1970 lays down specifications for fine aggregates from natural sources for concrete. According to which, the aggregates should be chemically inert strong, hard, durable and of limited porosity. The Sieve analysis was performed on the fine aggregates the results are as follows

The fine aggregate thus conforms to be of ZONE II according to IS 393-1970.

The specific gravity and Void content of the fine aggregates were determined as per method prescribed in IS: 2386 (Part III) -1963 .

Specific Gravity $=2.45$

Void Content $=29.29 \%$

\section{E. Coarse Aggregate}

Locally available crushed coarse aggregates were used. The properties of $20 \mathrm{~mm}$ and $10 \mathrm{~mm}$ coarse aggregates are as follows. The specific gravity and Void content of $20 \mathrm{~mm} \&$ $10 \mathrm{~mm}$ coarse aggregates were determined as per method prescribed in IS: 2386 (Part III) 1963. 
Specific Gravity, for 20mm $=2.74$

Void Content, for $20 \mathrm{~mm}=41.48 \%$

Specific Gravity, for $10 \mathrm{~mm}=2.74$

Void Content, for $10 \mathrm{~mm}=46.97 \%$
F. Water

Tapped municipal drinking water is used.

\section{MIX DESIGN}

The Mix Design Procedure As Prescribed In Is 10262:2009 And Using Is 456:2000 Was DEVELOPED For Grades M30 And M35 And The Weight Of Raw Materials (In Kg) Per M3 Of Concrete Mix For Different Grades Is

Shown Below In Table IV.

Table IV: Mix Design of Concrete M 30 Per Cubic Meter

\begin{tabular}{|c|c|c|c|c|c|c|c|}
\hline Grade & \multicolumn{2}{|c|}{$\begin{array}{c}\text { Total binding material } \\
\text { (380kg) }\end{array}$} & FA & $\begin{array}{l}\text { CA }(55 \%) \\
(20 \mathrm{~mm})\end{array}$ & $\begin{array}{l}\text { CA }(45 \%) \\
(10 \mathrm{~mm})\end{array}$ & Water & Plasticizer (\%) \\
\hline $\begin{array}{c}\mathrm{M}-30 \\
\left(\text { per } \mathbf{m}^{3}\right)\end{array}$ & $\begin{array}{c}\text { Cement } \\
380 \\
342 \\
304 \\
266 \\
247\end{array}$ & $\begin{array}{c}\text { GGBS } \\
0 \\
38 \\
76 \\
114 \\
133\end{array}$ & 657 & 660 & 539 & 168 & 1.1 \\
\hline
\end{tabular}

Table V: Mix Design of Concrete M 30 Per Batch

Grade

Total binding material

$(8.852 \mathrm{~kg})$

FA

CA

(20mm)

CA

Water

Plasticizer

(gm)

\begin{tabular}{ccccccc} 
& Cement & GGBS & & & & \\
& 8.85 & 0 & & & & \\
M-30 & 7.96 & 0.88 & 15.3 & 15.375 & 12.55 & 3.91 \\
(per batch) & 7.08 & 1.77 & & & & \\
& 6.19 & 2.65 & & & \\
& 5.75 & 3.09 & & & \\
\hline
\end{tabular}

Table VI: Mix Design of Concrete M 35 Per Cubic Meter

Grade

Total binding material

(400kg)
FA

CA (55\%)

(20mm)

CA $(45 \%)$

$(10 \mathrm{~mm})$

Water

Plasticizer

(\%)

\begin{tabular}{ccccccc}
\hline & Cement & GGBS & & & & \\
& 400 & 0 & & & & \\
M-35 & 360 & 40 & 650 & 653 & & 168 \\
$\left(\right.$ per $\left.\mathbf{~ m}^{3}\right)$ & 320 & 80 & & & \\
& 280 & 120 & & & \\
\hline
\end{tabular}

Table VII: Mix Design of Concrete M 35 Per Batch

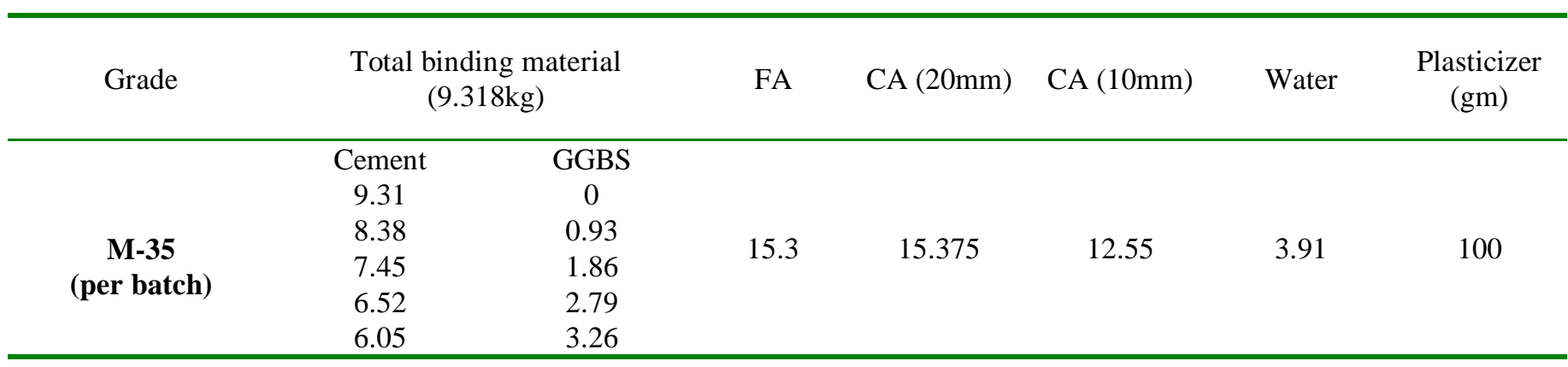

Retrieval Number: C6523029320/2020 CBEIESP DOI: 10.35940/ijeat.C6523.029320 
Mixing Procedure

First, the fine aggregates and cement in dry state were mixed for 3 to 5 minutes to have a uniform mixture. Thereafter the coarse aggregates were added and again mixed for 2 to 3 minutes. The water is added in two stages; firstly $3 \mathrm{~kg}$ water is added to the dry mix in the mixer and mixed thoroughly for 3 to 5 minutes and the remaining amount of water is mixed with the plasticizer and added to the mix while the mixing is still going on. The mixer is run for another 3 to 5 minutes as good quality mixes are formed with sufficient mixing time and energy.

The workability of the mix was such that the cone collapsed without segregation of concrete mix as observed in slump test.

\section{NOMENCLATURE OF CUBES}

The nomenclature of the cubes for identification of the cubes is decided as per Table VIII below.

Table VIII: Nomenclature of Cubes

\begin{tabular}{lll}
\hline S. & & \\
No & NOMENCLATURE & GRADE \\
. & & \\
\hline 1 & 0 GB30M & $0 \%$ GGBS M30 Grade \\
\hline
\end{tabular}

\begin{tabular}{lll}
\hline 2 & 1GB30M & 10\% GGBS M30 Grade \\
3 & 2GB30M & 20\% GGBS M30 Grade \\
4 & 3GB30M & $30 \%$ GGBS M30 Grade \\
5 & $3.5 G B 30 M$ & $35 \%$ GGBS M30 Grade \\
6 & 0 GB35M & $00 \%$ GGBS M35 Grade \\
7 & 1 GB35M & $10 \%$ GGBS M35 Grade \\
8 & 2 GB35M & $20 \%$ GGBS M35 Grade \\
9 & $3 G B 35 M$ & $30 \%$ GGBS M35 Grade \\
10 & $3.5 G B 35 M$ & $35 \%$ GGBS M35 Grade \\
\hline
\end{tabular}

The cubes subjected to normally cured cube specimens were tested for their compressive strength at ages of 3-day, 7-days and 28-days.

\section{RESULTS AND DISCUSSIONS}

Standard $150 \mathrm{~mm}$ mold was used, each layer compacted is tampered using a certified compacting rod, 25 tamps per layer is done. Once the 3 layers have been tampered, the concrete is leveled off using hand vibrator for complete compaction of concrete and after that a float or trowel is used to give a smooth surface that is flush with top of the mold. Procedure adopted is as prescribed by code IS 516:1959.

Table IX: - Compressive Strength of Cubes of M-30 Grade with \% Variation of GGBS

\begin{tabular}{|c|c|c|c|c|c|c|c|}
\hline \multirow[b]{2}{*}{ S.No } & \multirow{2}{*}{ NOMENCLATURE } & \multicolumn{6}{|c|}{ Compressive strength in $\mathrm{N} / \mathrm{mm}^{2}$} \\
\hline & & 3 day & Variation & 7 day & Variation & 28 day & Variation \\
\hline 1 & 0GB30M & 15.18 & & 26.38 & & 38.12 & \\
\hline 2 & 1GB30M & 15.60 & 2.76 & 28.22 & 6.97 & 39.80 & 4.40 \\
\hline 3 & 2GB30M & 16.42 & 8.16 & 31.25 & 18.46 & 40.42 & 6.03 \\
\hline 4 & 3GB30M & 14.9 & -1.84 & 28.58 & 8.33 & 35.21 & -7.86 \\
\hline 5 & 3.5GB30M & 13.18 & -13.7 & 24.32 & -7.80 & 32.12 & -15.73 \\
\hline
\end{tabular}

Table X: - Compressive Strength of Cubes of M-35 Grade with \% Variation of GGBS

Compressive strength in MPa

\begin{tabular}{|c|c|c|c|c|c|c|c|}
\hline \multirow[t]{2}{*}{ SNo } & \multirow[t]{2}{*}{ NOMENCLATURE } & \multicolumn{3}{|c|}{$\%$} & \multicolumn{2}{|l|}{$\%$} & \multirow{2}{*}{$\begin{array}{l}\% \\
\text { Variation }\end{array}$} \\
\hline & & 3 day & Variation & 7 day & Variation & 28 day & \\
\hline 1 & 0GB35M & 18.41 & & 32.15 & & 45.30 & \\
\hline 2 & 1GB35M & 19.25 & 4.56 & 33.22 & 3.33 & 46.10 & 1.76 \\
\hline 3 & 2GB35M & 20.40 & 10.8 & 35.29 & 9.76 & 49.20 & 8.61 \\
\hline 4 & 3GB35M & 20.10 & 9.17 & 33.58 & 4.44 & 44.20 & -2.42 \\
\hline 5 & 3.5GB35M & 17.60 & -4.39 & 31.65 & -1.55 & 42.25 & -6.73 \\
\hline
\end{tabular}




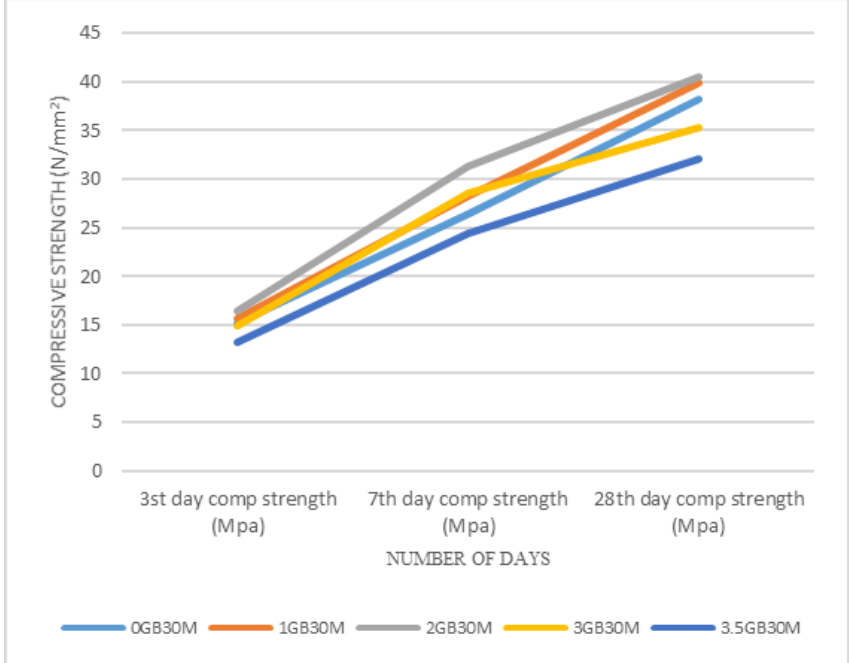

Graph 1: - Comparison of Compressive Strength of Cubes of M-30 Grade with \% Variation of GGBS

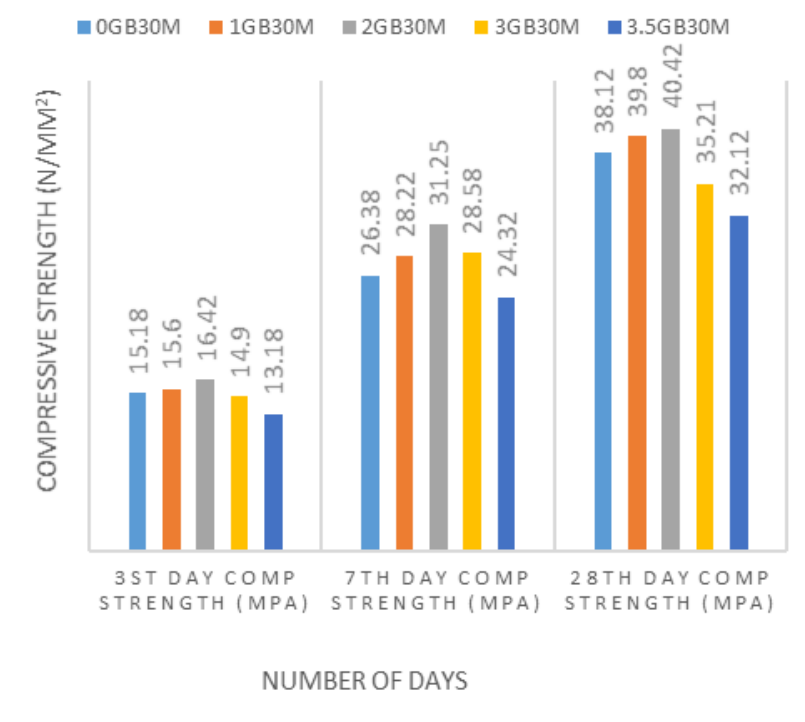

Bar Chart 1: - Comparison of Compressive Strength of Cubes of M-30 Grade with \% Variation of GGBS

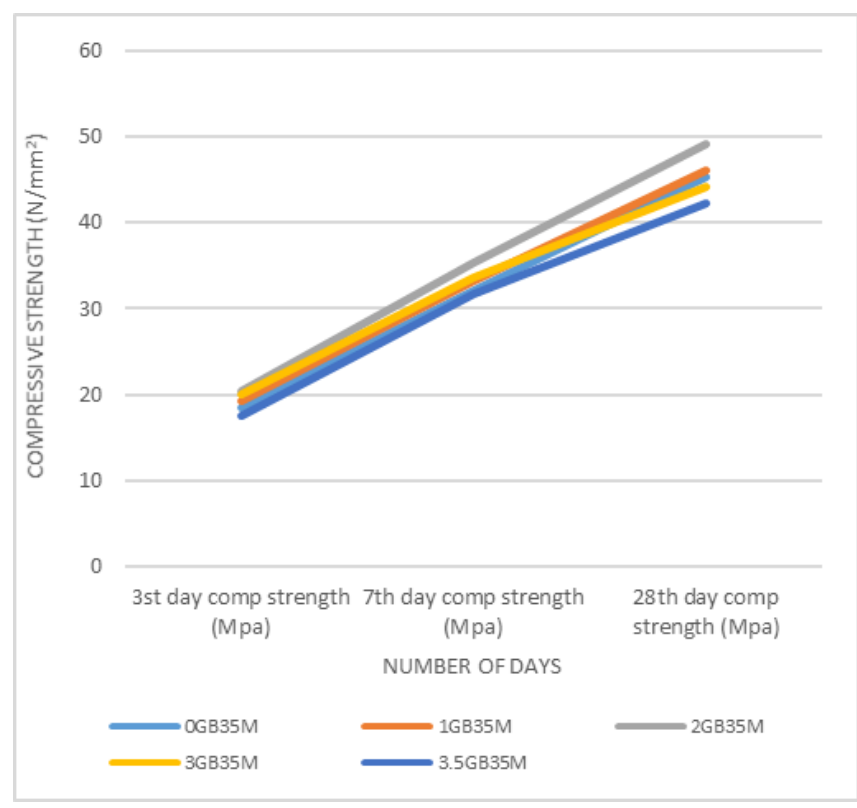

Graph 2: - Comparison of Compressive Strength of Cubes of M-35 Grade with \% Variation of GGBS

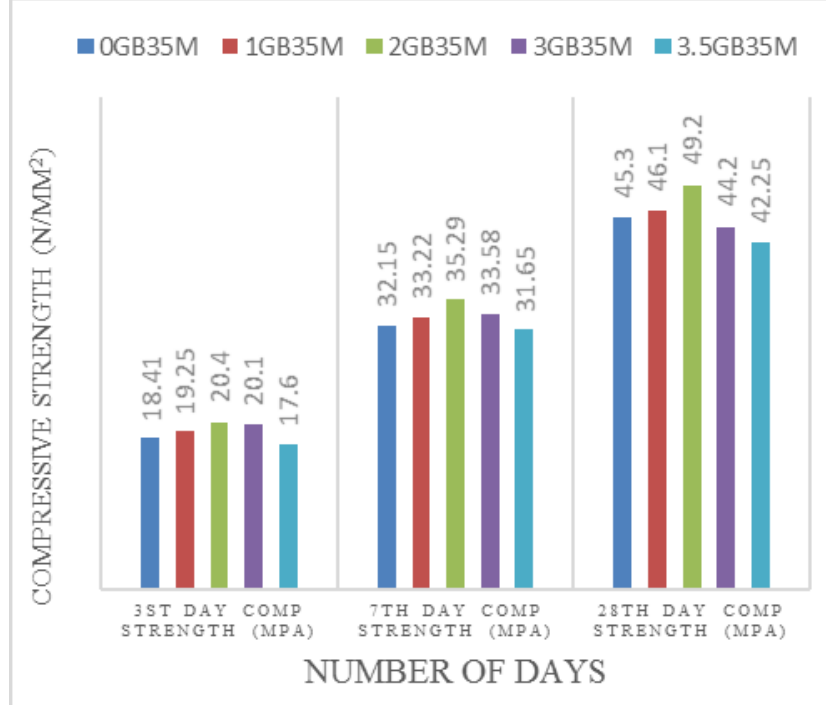

Bar Chart 2: - Comparison of Compressive Strength of Cubes of M-35 Grade with \% Variation of GGBS

Table XI: - Compression of compressive Strength of Cubes of M-30 Grade and M-35 with \% Variation of GGBS at $28^{\text {th }}$ Days

\begin{tabular}{|c|c|c|c|c|}
\hline S.No & NOMENCLATURE & $\begin{array}{l}28 \text { day comp strength } \\
\left(\mathrm{N} / \mathrm{mm}^{2}\right)\end{array}$ & NOMENCLATURE & $\begin{array}{l}28 \text { day comp strength } \\
\left(\mathrm{N} / \mathrm{mm}^{2}\right)\end{array}$ \\
\hline 1 & 0GB30M & 38.12 & 0GB35M & 45.30 \\
\hline 2 & 1GB30M & 39.80 & 1GB35M & 46.10 \\
\hline 3 & 2GB30M & 40.42 & 2GB35M & 49.20 \\
\hline 4 & 3GB30M & 35.21 & 3GB35M & 44.20 \\
\hline 5 & 3.5GB30M & 32.12 & 3.5GB35M & 42.25 \\
\hline
\end{tabular}

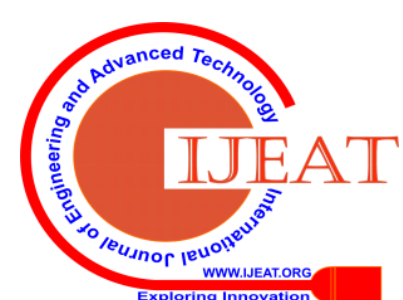




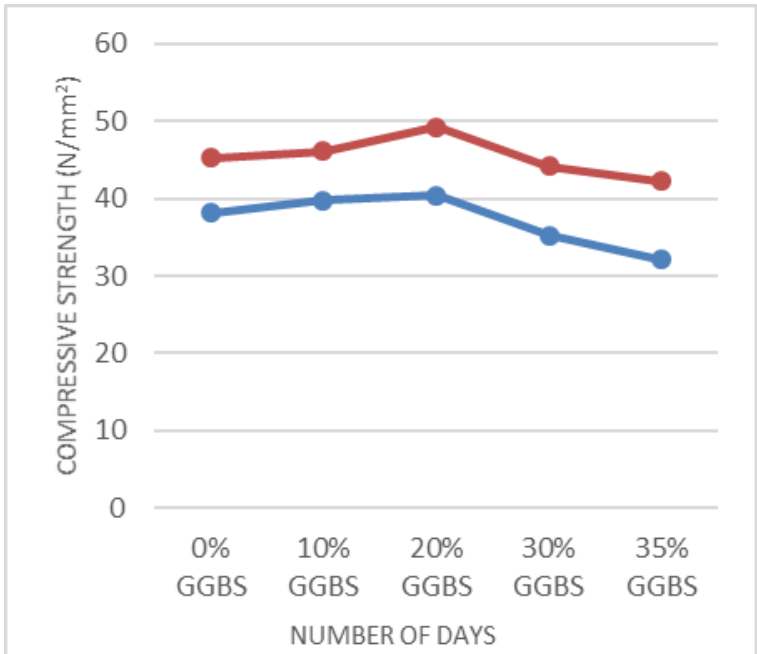

28 days comp strength of M30 $\longrightarrow 28$ days comp strength M35

Graph 3: - Compressive Strength of Cubes of M-30 And M35 at 28 Days with \% of GGBS Variation

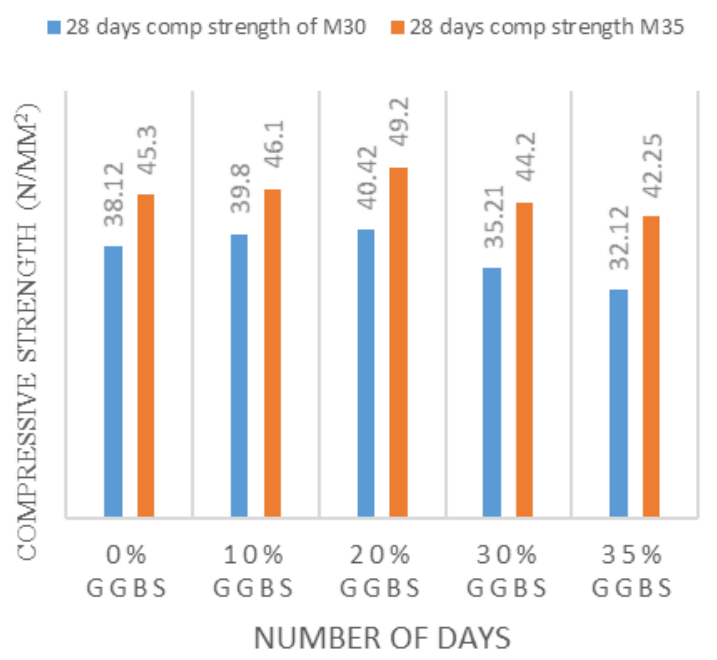

Bar Chart 3: - Compressive Strength of Cubes of M-30 and M35 at 28 Days with \% of GGBS Variation

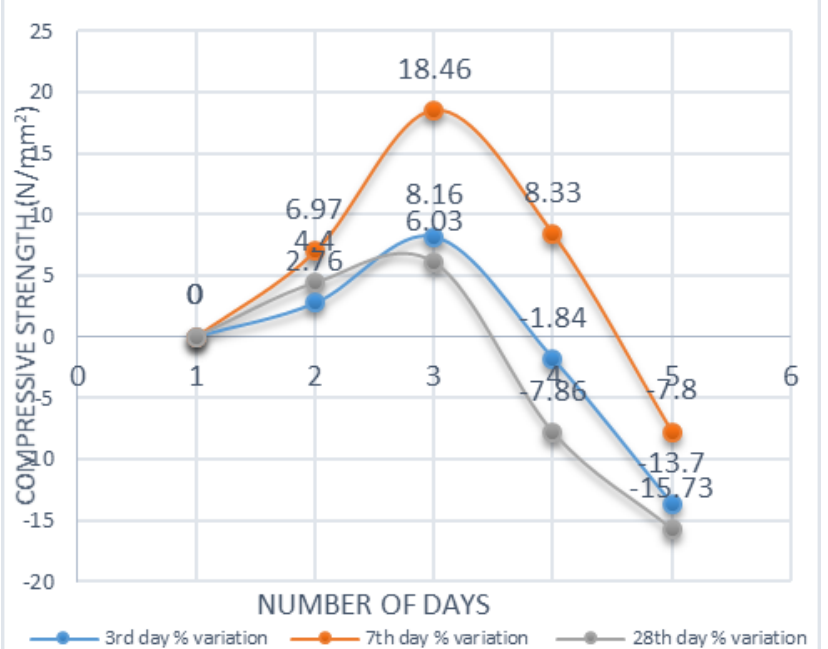

Graph 4: -The \% Variation of Compressive Strength of M30

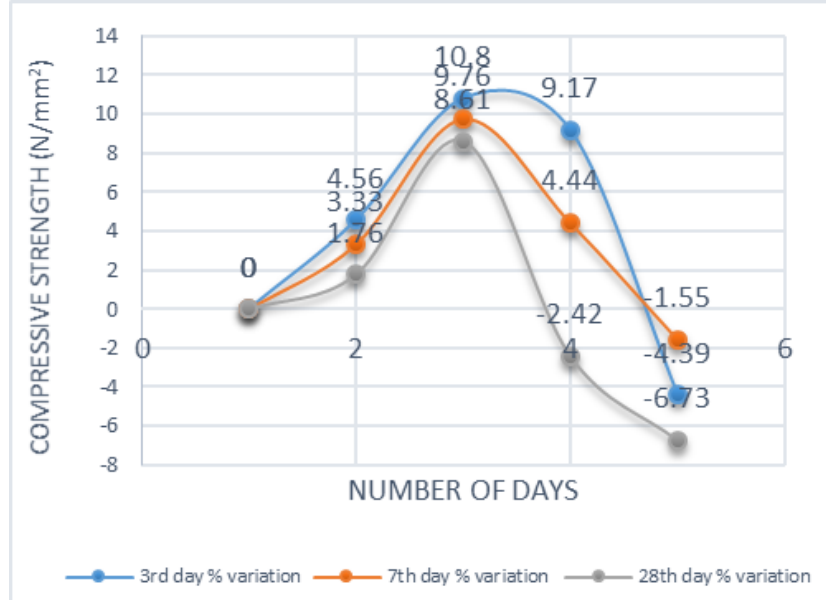

Graph 5: -The \% Variation of Compressive Strength of M35

\section{CONCLUSIONS}

From this experimental investigation, following conclusions are drawn:

With the addition of $20 \%$ of GGBS as partial replacement of Cement for M30 grade and M35 grade of concrete, there is an increase in compressive strength of concrete as compared to one where no replacement has been done.

The compressive strength of concrete cube after 28 days curing decreased at partial replacement percentage of 35 of ground granulated blast furnace slag (GGBS) with cement in both grade of concrete M30 and M35 as compared to cubes where no replacement was done.

It is also observed from the experimental work that the percentage increase in compressive strength of both grade of concrete mix (M 30 and M35) at initial days (7 days) is higher as compare to 28 days.

\section{ACKNOWLEDGMENT}

We are thankful to MHRD for PhD Assistantship at MBM Engineering College, JNVU Jodhpur, Rajasthan under TEQIP 3 (TEQIP 3 The Technical Education Quality Improvement Project (TEQIP III) is implemented by the Ministry of HRD, Government of India with focus on improving the quality of technical education).

\section{REFERENCES}

1. IS 10262:2009.

2. IS 456:2000.

3. IS $383: 1970$

4. IS 516:1959

5. European Journal of Scientific Research ISSN 1450-216X Vol.88 No-1 October, 2012, pp.155163@Euro journals Publishing, Inc. 2012 http://www.europeanjournalof scientific research.com.

6. Venu Malagavelliet.al./International Journal of Engineering Science and Technology Vol. 2(10), 2010, 5107-511.

7. ASTM C 989-940, Standard specification for ground granulated blast furnace slag for use in concrete and mortars

8. AvelineDarquennes, Stephanie Staquet, and Bernard Espion. (2011) "Behaviour of Slag Cement Concrete under Restraint Conditions". European Journal of Environmental and Civil Engineering, 15 (5), 787-798. 
9. Santosh Kumar Karri, G. V. Rama Rao, P. MarkandeyaRaju "Strength and Durability Studies on GGBS Concrete", SSRG International Journal of Civil Engineering (SSRG - IJCE), V2 (10), 34-41 October 2015. ISSN: 2348 - 8352. www.internationaljournalssrg.org/IJCE/index.html. Published by: Seventh Sense Research Group.

10. MojtabaValinejadShoubi, AzinShakiba Borough, and OmidrezaAmirsoleimani. (2013). "Assessment of the Roles of Various Cement Replacements in Achieving Sustainable and High-Performance Concrete". International Journal of Advances in Engineering and Technology, 6 (1): 68-77.

11. Reginald B. Kogbara, and Abir Al-Tabbaa. (2011). "Mechanical and Leaching Behaviour of Slag-Cement and Limeactivated Slag Stabilized/Solidified Contaminated Soil". The science of the Total Environment, 409 (11), 2325-2335.

\section{AUTHORS PROFILE}

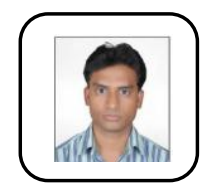

Praveen Kumar Gahlot ${ }^{1} \mathrm{PhD}$ scholar, structural department, in MBM Engineering College, Jai Narain Vyas University Jodhpur.

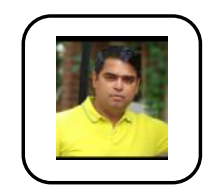

Dr Suresh Singh Sankhla, Associate Professor, structural Department, MBM Engineering College, Jai Narain Vyas University Jodhpur, Rajasthan.

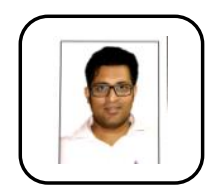

Krishan Kumar Saini, $\mathrm{PhD}$ scholar, structural department, in MBM Engineering College, Jai Narain Vyas University Jodhpur. 